\title{
Memantine Therapy of Behavioral Symptoms in Community-Dwelling Patients with Moderate to Severe Alzheimer's Disease
}

\author{
George T. Grossberg ${ }^{a}$ Vojislav Pejović ${ }^{b}$ Michael L. Miller ${ }^{b}$ Stephen M. Graham ${ }^{c}$ \\ a Department of Neurology and Psychiatry, Saint Louis University School of Medicine, St. Louis, Mo., \\ ${ }^{b}$ Prescott Medical Communications Group, Chicago, III., and ${ }^{\mathrm{C}}$ Forest Research Institute, Jersey City, N.J., USA
}

\section{Key Words}

Memantine $\cdot$ Alzheimer's disease $\cdot$ Behavioral disturbances • Agitation $\cdot$ Aggression $\cdot$ Antipsychotics

\begin{abstract}
Memantine is a moderate-affinity, uncompetitive antagonist of N-methyl-D-aspartate receptors, approved for the treatment of moderate to severe Alzheimer's disease (AD). Available data suggest that, in addition to its benefits on cognition, function, and global status, memantine treatment may also help alleviate behavioral symptoms. This article provides an overview of the prevalence, assessment, and treatment of behavioral disturbances in $A D$, and summarizes current knowledge regarding the effects of memantine on the behavior of community-dwelling patients. We searched EMBASE and PubMed (January 1992 to October 2008) for reports on memantine trials that involved outpatients with moderate to severe AD. All previously unpublished data were obtained from Forest Laboratories, Inc. Behavioral outcomes were assessed in three completed, double-blind, placebo-controlled trials. Overall, patients who received memantine performed better on behavioral measures than those treated with placebo. Post-hoc analyses suggest that memantine treatment was associated with
\end{abstract}

a reduced severity or emergence of specific symptoms, particularly agitation and aggression. Prospective, well-designed trials are warranted to evaluate the efficacy of memantine in patients with significant behavioral symptoms.

Copyright $\odot 2009$ S. Karger AG, Basel

\section{Introduction}

While memory loss and cognitive decline are often seen as the hallmark symptoms of Alzheimer's disease (AD), behavioral disturbances contribute significantly to the overall burden of the disease. Behavioral symptoms in $\mathrm{AD}$ can be classified as psychotic (delusions and hallucinations) or nonpsychotic (apathy, depression, agitation, aggression, anxiety, irritability, and aberrant motor behavior), all of which can cause significant distress for the patient and caregiver. In patients with $\mathrm{AD}$, the severity of most behavioral disturbances is associated with the severity of dementia $[1,2]$; in addition, the presence of psychosis (i.e. delusions and hallucinations) has been shown to be predictive of functional decline [3]. The presence of behavioral symptoms in general increases the likelihood of patient placement into long-term care facilities, which increases the costs of patient care [4-8].

\section{KARGER}

Fax +4161306 1234 E-Mail karger@karger.ch www.karger.com
George T. Grossberg, MD

Department of Neurology and Psychiatry, Saint Louis University School of Medicine 1438 South Grand Boulevard

St. Louis, MO 63104 (USA)

Tel. +1 314977 4829, Fax +1 314977 4878, E-Mail grossbgt@slu.edu 
Therefore, the attenuation of behavioral disturbances represents an important goal in the management of AD.

Behavioral problems in patients with $\mathrm{AD}$ are managed using both pharmacological $[9,10]$ and nonpharmacological [11-14] interventions. Recent studies suggest that drugs currently approved to treat cognitive symptoms in $\mathrm{AD}$ (cholinesterase inhibitors and memantine) may also have psychotropic effects $[5,15]$. Memantine, an N-methyl-D-aspartate receptor antagonist approved for the treatment of patients with moderate to severe $\mathrm{AD}$, is believed to improve glutamatergic neurotransmission and reduce the damaging effects caused by excessive glutamate stimulation [16]. In addition to benefits on cognition [17-19], memantine may play a role in preventing and alleviating behavioral symptoms associated with AD [20,21].

This review summarizes the behavioral disturbances associated with $\mathrm{AD}$ and the effectiveness of memantine treatment on behavioral outcomes in clinical trials involving community-dwelling patients.

\section{Behavioral Disturbances in AD: Prevalence and Characterization}

The prevalence of behavioral symptoms in $\mathrm{AD}$ varies by study. Several estimates predict that approximately $90 \%$ of patients with AD will develop at least one behavioral symptom over the course of the disease [22-25], and more than 75\% will develop two or more symptoms [22]. Available evidence suggests that the distribution and reporting of behavioral problems among patients with dementia are very complex, and that reported symptoms may depend on factors such as a patient's race [24] or characteristics of the caregiver [26]. In some patients with $\mathrm{AD}$, behavioral disturbances emerge early in the disease, possibly before the diagnosis $[27,28]$. In general, the symptoms become more severe as the disease progresses [2], with apathy, anxiety, depression, irritability, and agitation being the most frequent [29]. For a summary of behavioral symptom characteristics, associated neuropathology, and prevalence in $\mathrm{AD}$, please refer to online supplementary table 1 (www.karger.com/doi/10.1159/ 000200013).

In an effort to group the behavioral disturbances observed in $\mathrm{AD}$, the term 'behavioral and psychological symptoms of dementia' was created [8]. However, this category has been considered too broad for either diagnostic or regulatory purposes, and several organizations support the development of diagnostic criteria for more specific syndromes of $\mathrm{AD}[30,31]$. Provisional criteria have been developed for psychosis of $\mathrm{AD}$ [32] and depression of $\mathrm{AD}$ [28], with the former receiving the most support and use [30, 31, 33, 34].

\section{Treatment}

Current strategies to manage behavioral problems in patients with $\mathrm{AD}$ include the use of pharmacological [10, $11,35-41]$ and behavioral interventions $[11-14,42]$. Commonly prescribed drugs include antidepressants, antipsychotics, anticonvulsants, and anxiolytics [42, 43]; however, these pharmacological agents are not specifically indicated for use in patients with AD. A summary of properties of agents used for the treatment of behavioral problems in $\mathrm{AD}$ can be found in supplementary table 2 (www.karger.com/doi/10.1159/000200013).

The potential benefits of adjunct pharmacotherapy should be weighed against the risks of polypharmacy, the higher cost of treatment, and the increased possibility of noncompliance. A recent study of patients with dementia in nursing homes and acute geriatric wards indicated that $87 \%$ of patients in the study were taking at least one psychotropic medication, and $11 \%$ were taking four or more; the mean number of drugs used by patients with dementia was 8.4 [23]. Recent concerns, particularly those regarding a potentially increased risk of stroke and allcause mortality associated with both conventional [44, 45] and atypical [46-48] antipsychotic use in elderly patients with dementia, have led to a re-evaluation of antipsychotic use in patients with less severe behavioral problems. The authors of the recently completed Clinical Antipsychotic Trials of Intervention Effectiveness Project in patients with AD (CATIE-AD) [46] concluded that the potential efficacy of atypical antipsychotic drugs for the treatment of psychosis, aggression, or agitation in patients with AD is offset by an increased possibility of adverse effects.

Current treatment guidelines suggest taking a stepwise approach to alleviating behavioral symptoms, beginning with nonpharmacological methods and adding atypical antipsychotic medications only in instances of severe behavioral problems [49]. Consequently, medications traditionally used to treat cognitive deficits in $\mathrm{AD}$ are now being investigated for efficacy in treating the behavioral symptoms of the disease. Since memantine is approved for patients in moderate to severe stages of $\mathrm{AD}[17$, $18,50]$, and since such patients are very likely to experience behavioral problems, the behavioral benefits of memantine may be of considerable interest. 


\section{Methods}

To summarize the effects of memantine treatment on behavioral symptoms in $\mathrm{AD}$, we conducted a search of all papers published between January 1992 and October 2008, according to EMBASE/Medline databases. The search was performed using the terms 'memantine AND (moderate OR severe) AND Alzheimer', with search limitations of articles in English, clinical trials, meta-analyses, and randomized controlled trials (PubMed and EMBASE) and Cochrane reviews (EMBASE). Studies with patients residing in nursing homes or assisted living facilities were excluded, since these patients may have significantly different baseline characteristics (severity of dementia, behavioral symptoms, concomitant medications, level of independence, etc.). To determine the quality of reporting in these studies, we compared them with the 2001 Consolidated Standards of Reporting Trials (CONSORT) Statement $[51,52]$. Behavioral data were extracted from primary study reports, as well as from post-hoc, pooled, and meta-analyses; any unpublished supplemental information was provided by Forest Laboratories, Inc. For the purpose of this review, Cohen's d effect sizes were calculated by Forest Research Institute, using the pre-specified intent to treat (ITT) population, mean values of change from baseline to endpoint, pooled standard deviations, and the last observation carried forward (LOCF) approach.

\section{Memantine: Efficacy in Treating Behavioral Symptoms}

From January 1992 to October 2008, a total of three double-blind, placebo-controlled memantine studies conducted in community-dwelling patients with moderate to severe $\mathrm{AD}$ were registered with EMBASE and PubMed $[17,18,53]$. The study reports for all three trials conformed with a majority of the 22 recommendations outlined in the 2001 CONSORT Statement (table 1) [51, 52].

In the three memantine trials $[17,18,53]$, two scales were used to measure behavioral symptom changes: the Neuropsychiatric Inventory (NPI) and the Behavioral Rating Scale for Geriatric Patients (BGP). The NPI is a validated outcome measure designed to assess behavioral symptoms in patients with $\mathrm{AD}$ and other dementias [54, 55]. It covers 12 behavioral domains: agitation, irritability, anxiety, dysphoria, hallucinations, delusions, apathy, euphoria, disinhibition, aberrant motor behavior, nighttime disturbances, and appetite and eating abnormalities. The frequency and severity of each symptom are recorded, with each domain contributing a maximum of 12 points (higher score reflects greater impairment), for a maximum total score of 144 . The NPI was used in all three memantine trials involving community-dwelling patients with moderate to severe $\operatorname{AD}[17,18,53]$.
The BGP [56, 57], widely used in European clinical trials (including a memantine trial involving institutionalized patients with dementia [50]), was also an assessment tool in two of the three US-based memantine trials in outpatients with moderate to severe $\operatorname{AD}[18,53]$. This scale is a Dutch translation and adaptation of the Stockton Geriatric Rating Scale, which has subsequently been re-translated into English and other languages. The BGP-Care Dependency subscale assesses cognitive and functional characteristics associated with increased need for care. The maximum score on this subscale is 46 ; a higher score indicates greater impairment.

\section{Individual Trials: Total NPI Score}

Three trials met the inclusion criteria: MRZ-900019605, authored by Reisberg et al. [17], MEM-MD-01 by van Dyck et al. [53], and MEM-MD-02 by Tariot et al. [18]. The trial by Reisberg et al. [17] used only the NPI as a behavior assessment tool, and the trials by van Dyck et al. [53] and Tariot et al. [18] utilized both the NPI and BGP $[18,53]$. The basic properties of these studies, including a summary of behavioral outcomes and effect sizes, are presented in table 2 .

The trials by Reisberg et al. [17] and van Dyck et al. [53] found no statistically significant differences between memantine and placebo groups at study endpoint on the NPI total score, although the mean NPI score of the memantine-treated group in the Reisberg et al. [17] study remained stable over the course of the trial, while the placebo-treated group showed a slight clinical decline. In the study by Tariot et al. [18], patients treated with memantine and donepezil significantly outperformed patients treated with placebo and donepezil on the total NPI score at both week 12 and study endpoint $[18,58]$.

\section{Individual NPI Items}

A post-hoc analysis of individual NPI items revealed a significant advantage for memantine therapy over placebo at study endpoint on the item of agitation/aggression in the studies by Reisberg et al. [17] and Tariot et al. $[18,58,59]$; in the trial by van Dyck et al. [53], the benefit was significant at week 12 (last observation carried forward analysis), but not at endpoint. In addition, memantine therapy in the study by Tariot et al. [18] was found to provide a significant advantage at study endpoint on the items of irritability/lability and appetite/eating change, and on the item of delusions in the trial by Reisberg et al. $[17,58,59]$ (table 2). Placebo-treated patients did not show significant advantages over memantine-treated patients on any item in any of the 3 studies. 


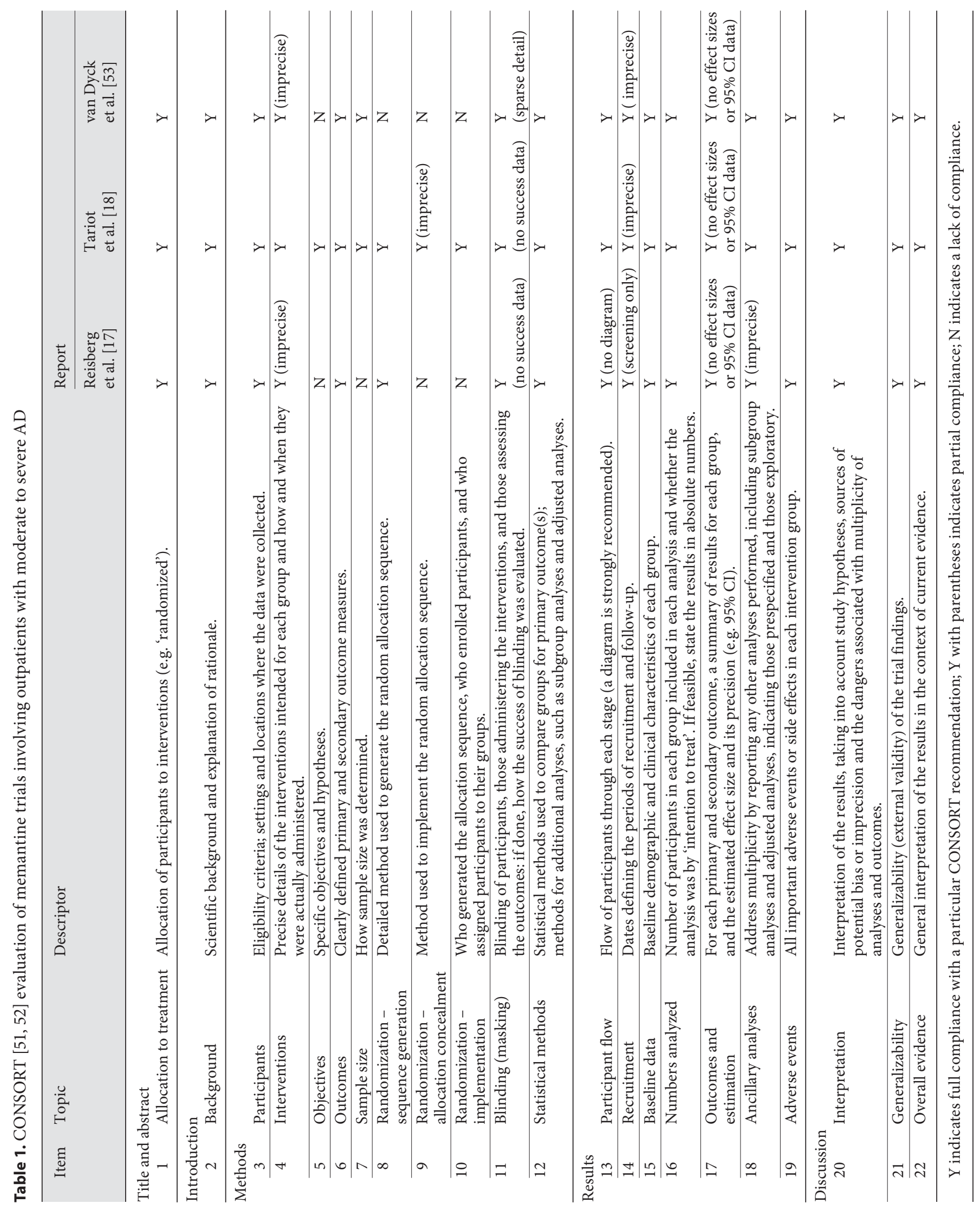


Table 2. Summary of double-blind, placebo-controlled memantine trials involving outpatients with moderate to severe AD

\begin{tabular}{|c|c|c|c|c|c|c|c|c|}
\hline Study ${ }^{\mathrm{a}}$ & Trial design & $\begin{array}{l}\text { Psychoactive } \\
\text { drug use }\end{array}$ & $\begin{array}{l}\text { Behavioral } \\
\text { outcome } \\
\text { measure }\end{array}$ & $\begin{array}{l}\text { Treatment } \\
\text { groups }\end{array}$ & $\begin{array}{l}\text { Score at } \\
\text { baseline }^{b}\end{array}$ & $\begin{array}{l}\text { Mean score } \\
\text { change from } \\
\text { baseline at } \\
\text { endpoint }^{\mathrm{b}}\end{array}$ & $\begin{array}{l}\text { Effect size } \\
(95 \% \mathrm{CI})^{\mathrm{c}}\end{array}$ & $\begin{array}{l}\text { Significant } \\
\text { individual } \\
\text { domains }\end{array}$ \\
\hline $\begin{array}{l}\text { Reisberg } \\
\text { et al. [17] }\end{array}$ & $\begin{array}{l}28 \text { weeks } \\
20 \mathrm{mg} / \text { day } \\
\mathrm{n}=252 \\
\text { monotherapy }\end{array}$ & $\begin{array}{l}\text { no antipsychotics, } \\
\text { anxiolytics, or } \\
\text { neuroleptics } \\
\text { permitted }\end{array}$ & NPI & $\frac{\text { Pbo }}{\text { Mem }}$ & $\begin{array}{l}19.5 \\
21.4\end{array}$ & $\begin{array}{l}3.6 \\
0.4\end{array}$ & $\begin{array}{l}-0.21 \\
(-0.45,0.04)\end{array}$ & $\begin{array}{l}\text { delusions* }{ }^{*}[59] \\
\text { agitation/aggression }^{* *}[59]\end{array}$ \\
\hline $\begin{array}{l}\text { Tariot } \\
\text { et al. [18] }\end{array}$ & $\begin{array}{l}24 \text { weeks } \\
20 \mathrm{mg} / \text { day } \\
\mathrm{n}=404 \\
\text { combination } \\
\text { therapy }\end{array}$ & $\begin{array}{l}\text { - antidepressants: } \\
\text { Pbo/Don, 36\%; } \\
\text { Mem/Don, 36\% } \\
\text { - anxiolytics or } \\
\text { neuroleptics: } \\
\text { Pbo/Don, 26\%; } \\
\text { Mem/Don, 22\% }\end{array}$ & $\overline{\mathrm{BGP}^{* * *}}$ & $\begin{array}{l}\frac{\text { Pbo/Don }}{\text { Mem/Don }} \\
\frac{\text { Pbo/Don }}{\text { Mem/Don }}\end{array}$ & \begin{tabular}{|l|}
13.6 \\
13.4 \\
$13.4^{\mathrm{c}}$ \\
$13.0^{\mathrm{c}}$
\end{tabular} & $\begin{array}{r}3.60 \\
-0.24 \\
3.1^{\mathrm{c}} \\
1.0^{\mathrm{c}}\end{array}$ & $\begin{array}{l}-0.30 \\
(-0.51,-0.10) \\
-0.34 \\
(-0.55,-0.13)\end{array}$ & $\begin{array}{l}\text { agitation/aggression }{ }^{* *}[58,59] \\
\text { irritability/lability }{ }^{* *}[58,59] \\
\text { appetite/eating change } *[58,59]\end{array}$ \\
\hline $\begin{array}{l}\text { van Dyck } \\
\text { et al. [53] }\end{array}$ & $\begin{array}{l}24 \text { weeks } \\
20 \mathrm{mg} / \text { day } \\
\mathrm{n}=350 \\
\text { monotherapy }\end{array}$ & $\begin{array}{l}\text { - antidepressants: } \\
\text { Pbo, 29\%; } \\
\text { Mem, 32\% } \\
\text { - anxiolytics or } \\
\text { neuroleptics: } \\
\text { Pbo, 31\%; } \\
\text { Mem, 30\% }\end{array}$ & $\overline{\mathrm{BGP}}$ & $\begin{array}{l}\frac{\text { Pbo }}{\text { Mem }} \\
\frac{\text { Pbo }}{\text { Mem }}\end{array}$ & $\begin{array}{l}17.5 \\
20.3 \\
16.7 \\
17.3\end{array}$ & $\begin{array}{r}-0.2^{\mathrm{c}} \\
-1.0^{\mathrm{c}} \\
1.4^{\mathrm{c}} \\
0.6^{\mathrm{c}}\end{array}$ & $\begin{array}{l}-0.05 \\
(-0.27,0.17) \\
-0.14 \\
(-0.37,0.09)\end{array}$ & $\begin{array}{l}\text { none }^{\mathrm{c}} \\
\text { none }\end{array}$ \\
\hline
\end{tabular}

A post-hoc analysis that focused solely on the Tariot et al. [18] study reported that in patients who were asymptomatic at baseline for each individual symptom of agitation/aggression, irritability/lability, and nighttime behavioral disturbances, a significantly lower proportion of memantine-treated patients demonstrated an emergence of these symptoms compared to patients treated with placebo [58]. No NPI symptoms emerged in a significantly higher proportion of memantine-treated patients [58]. In addition, memantine-treated patients who demonstrated agitation at baseline experienced a significant mean improvement at endpoint on this NPI item, compared to their placebo-treated counterparts [58]. It should be noted, however, that the trial was not designed to examine differences in individual NPI items, and that baseline matching of the two groups was not performed according to individual NPI item scores.

\section{Pooled Analyses and Meta-Analyses: Total NPI Score}

Two approaches have been employed in combining trial data for the purpose of meta-analysis in memantine studies in moderate to severe AD. In the first approach, used by McShane et al. [19] and Doody et al. [60], the dataset was created by compiling data from all three 6month, placebo-controlled trials of memantine in moderate to severe $\mathrm{AD}$ that used the NPI $[17,18,53]$. The study group was then analyzed for the effects of memantine treatment on overall behavioral symptomatology (i.e. the mean change from baseline of the total NPI score). Both studies used the same statistical tools, and both found an overall significant (and homogeneous) advantage of memantine over placebo.

In the second approach, utilized in a meta-analysis by Winblad et al. [61], the data from memantine trials in moderate to severe $\mathrm{AD}[17,18,53]$ were combined with those of patients from the three memantine trials in mild to moderate AD [62-64] who were in the moderate stage of the disease (baseline MMSE score of 19 or below). The second approach also demonstrated a significant benefit of memantine over placebo on the total NPI score [61]. 
Pooled Analyses and Meta-Analyses: Individual NPI Items and Item Clusters

The two approaches outlined above were also used in meta-analyses that focused on the efficacy of memantine on individual behavioral symptoms in patients with moderate to severe AD. An analysis by Cummings and Olin [65] examined the data from all participants in the trials by Reisberg et al. [17], van Dyck et al. [53], and Tariot et al. [18], and found that three NPI domains demonstrated homogeneous, statistically significant treatment differences in favor of memantine: delusions, agitation/ aggression, and irritability/lability. The other individualitem meta-analysis by Gauthier et al. [20] utilized the data of all the participants from the trials of Reisberg et al. [17], van Dyck et al. [53], and Tariot et al. [18], together with those of patients from the three memantine trials in mild to moderate $\mathrm{AD}$ [62-64] who were in the moderate stage of the disease (baseline MMSE score of 19 or below). This study also found that the memantine-treated patients demonstrated a significantly lower mean score change from baseline at endpoint (i.e. better performance) than the placebo-treated patients on the NPI items of delusions, agitation/aggression, and irritability/lability, as well as on a fourth item, hallucinations [20]. Memantine treatment also significantly reduced the emergence of agitation/aggression, irritability/lability, and nighttime behavior [20], according to this analysis.

An additional report by Wilcock et al. [21], which combined the data from the three memantine trials in moderate to severe $\mathrm{AD}[17,18,53]$, looked at all the patients from those trials who experienced agitation/aggression or psychosis at baseline (i.e. had a score $>0$ on at least one of the following NPI items: agitation/aggression, delusions, and hallucinations). The study found that, at endpoint and at week 12, memantine-treated patients with baseline symptoms of either agitation/aggression or psychosis demonstrated a significant improvement on that symptom cluster compared to their placebo-treated counterparts, both in terms of the mean score change from baseline and in terms of the proportion of patients who demonstrated a clinical improvement [21].

\section{Discussion}

Collectively, these findings suggest that 6 months of memantine treatment significantly reduce behavioral disturbances in outpatients with moderate to severe AD. This conclusion is further strengthened by the results of a recently completed 24-week, double-blind, placebo- controlled trial of an extended-release memantine formulation ( $28 \mathrm{mg} /$ day, once daily), involving $676 \mathrm{commu}-$ nity-dwelling patients with moderate to severe $\mathrm{AD}$ who were receiving concurrent, stable treatment with a cholinesterase inhibitor [66]. The group treated with memantine demonstrated a mean (SD) baseline to endpoint improvement of 4.3 (14.6) points on the total NPI, which was significantly greater than an improvement of 1.6 (12.7) points observed in the placebo group (LOCF; $\mathrm{p}=$ $0.005)$ [66]. These results were presented at the 2008 International Conference on Alzheimer's Disease (ICAD), and at the time of this review have not been published in a peer-review journal.

The consistent effect of memantine on symptoms of agitation/aggression may be of particular significance in the treatment of $\mathrm{AD}$. According to multiple reports, aggressive behavior and agitation occur in approximately $30 \%$ of all patients with dementia $[29,67]$ and are correlated with an increased risk of nursing home placement [68]. Such symptoms are traditionally treated with antipsychotic medications; however, recent guidelines advise against using antipsychotics in elderly patients, due to an increased likelihood of serious cerebrovascular events $[46,48]$. Therefore, the consistently reported alleviation of agitation and aggression in memantine-treated outpatients with moderate to severe $\mathrm{AD}$ merits further investigation, particularly if delay of institutionalization is a possible outcome. It should be noted that a recent trial of this nature, specifically designed to assess treatment benefits of the cholinesterase inhibitor donepezil in patients with moderate to severe $\mathrm{AD}$ who experienced clinical agitation, failed to show a significant advantage of donepezil treatment over placebo [69].

\section{Limitations}

With the exception of studies conducted in institutionalized patients (e.g. a trial of memantine involving nursing home residents with dementia [50]), most AD trials exclude patients with significant behavioral disturbances at screening. Although some patients subsequently develop behavioral symptoms during the trial, the participants typically do not express the range of disturbances generally seen in AD. This is particularly the case for trials involving patients with moderate to severe $\mathrm{AD}$, as baseline NPI scores in these studies are relatively low compared to what is typically seen in such patients. Therefore, the information obtained in these studies cannot be readily extended to patients in naturalistic settings, since such patients are likely to experience severe behavioral symptoms. In addition, the trials were not de- 
signed to detect differences between groups on individual NPI items.

Although all trial groups were generally balanced in terms of psychotropic use, it cannot be ruled out that concomitant medications may have acted as a confounding factor in analyzing behavioral symptomatology. To properly assess the effectiveness of memantine in alleviating and preventing behavioral disturbances, clinical trials involving patients who meet specific behavioral criteria and concomitant medication restrictions are warranted.

\section{Conclusion}

Considering the prevalence, high cost, and negative impact of behavioral problems in $\mathrm{AD}$, coupled with the risks associated with polypharmacy, it is important to consider whether the currently prescribed AD treatments can provide behavioral benefits. Current data provide evidence that memantine, in addition to its effects on cognition and daily functioning, may be efficacious in alleviating or preventing behavioral symptoms in patients with moderate to severe $\mathrm{AD}$ who are still living in the community. The consistent effect of memantine treatment on agitation/aggression and irritability/lability across multiple trials and in meta-analyses is notable. Prospective, randomized, placebo-controlled trials in outpatient settings using behavior as the primary outcome are warranted, so that we may better understand the clinical impact of these drugs.

\section{Acknowledgements}

The authors would like to thank Michael Tocco, PhD, Hai-An Hsu, PhD, Jason T. Olin, PhD, and Eugene Schneider, MD, of Forest Laboratories (the latter two being former employees), and Christine H. Wichems, $\mathrm{PhD}$, Jennifer Hepker, $\mathrm{PhD}$, and Merrilee Johnstone, PhD, of Prescott Medical Communications Group, for their contributions to this report.

All individuals acknowledged for assisting on this report have agreed to be listed as contributors.

G.T.G. discloses that he has received consulting fees, honoraria, and grant funding from Forest Laboratories, Inc. S.M.G. is an employee of Forest Research Institute, Inc. V.P. and M.L.M. are employees of Prescott Medical Communications Group, a contractor and consultant to Forest Research Institute.

\section{References}

1 Miller TP, Tinklenberg JR, Brooks JO 3rd, Fenn HH, Yesavage JA: Selected psychiatric symptoms associated with rate of cognitive decline in patients with Alzheimer's disease. J Geriatr Psychiatry Neurol 1993;6:235-238.

$\checkmark 2$ Lopez OL, Becker JT, Sweet RA, Klunk W, Kaufer DI, Saxton J, Habeych M, DeKosky ST: Psychiatric symptoms vary with the severity of dementia in probable Alzheimer's disease. J Neuropsychiatry Clin Neurosci 2003; $15: 346-353$

-3 Scarmeas N, Brandt J, Albert M, Hadjigeorgiou G, Papadimitriou A, Dubois B, Sarazin M, Devanand D, Honig L, Marder K, Bell K, Wegesin D, Blacker D, Stern Y: Delusions and hallucinations are associated with worse outcome in Alzheimer disease. Arch Neurol 2005;62:1601-1608.

4 Harwood DG, Barker WW, Ownby RL, Duara R: Relationship of behavioral and psychological symptoms to cognitive impairment and functional status in Alzheimer's disease. Int J Geriatr Psychiatry 2000;15:393400.

5 Grossberg GT: The ABC of Alzheimer's disease: behavioral symptoms and their treatment. Int Psychogeriatr 2002;14(suppl 1):2749.

\section{Beeri MS, Werner P, Davidson M, Noy S: The cost of behavioral and psychological symp- toms of dementia (BPSD) in community dwelling Alzheimer's disease patients. Int J Geriatr Psychiatry 2002;17:403-408. \\ -7 Murman DL, Chen Q, Powell MC, Kuo SB, Bradley CJ, Colenda CC: The incremen- tal direct costs associated with behavioral symptoms in AD. Neurology 2002;59:1721- 1729.}

8 Finkel SI: Behavioral and psychological symptoms of dementia: a current focus for clinicians, researchers, and caregivers. J Clin Psychiatry 2001;62(suppl 21):3-6.

-9 Beier MT: Pharmacotherapy for behavioral and psychological symptoms of dementia in the elderly. Am J Health Syst Pharm 2007;64: S9-S17; quiz S24-S25.

10 Sultzer DL: Psychosis and antipsychotic medications in Alzheimer's disease: clinical management and research perspectives. Dement Geriatr Cogn Disord 2004;17:78-90.

- 11 Silvestri A, Rosano G, Zannino G, Ricca F, Marigliano V, Fini M: Behavioral disturbances in Alzheimer's disease: a non-pharmacological therapeutic approach. Arch Gerontol Geriatr Suppl 2004;379-386.
12 Svansdottir HB, Snaedal J: Music therapy in moderate and severe dementia of Alzheimer's type: a case-control study. Int Psychogeriatr 2006;18:613-621.

13 Verkaik R, van Weert JC, Francke AL: The effects of psychosocial methods on depressed, aggressive and apathetic behaviors of people with dementia: a systematic review. Int J Geriatr Psychiatry 2005;20:301-314.

14 Haupt M, Karger A, Janner M: Improvement of agitation and anxiety in demented patients after psychoeducative group intervention with their caregivers. Int J Geriatr Psychiatry 2000;15:1125-1129.

15 Wynn ZJ, Cummings JL: Cholinesterase inhibitor therapies and neuropsychiatric manifestations of Alzheimer's disease. Dement Geriatr Cogn Disord 2004;17:100-108.

16 Parsons CG, Stöffler A, Danysz W: Memantine: a NMDA receptor antagonist that improves memory by restoration of homeostasis in the glutamatergic system - too little activation is bad, too much is even worse. Neuropharmacology 2007;53:699-723.

17 Reisberg B, Doody R, Stöffler A, Schmitt F, Ferris S, Möbius HJ: Memantine in moderate-to-severe Alzheimer's disease. N Engl J Med 2003;348:1333-1341. 
18 Tariot PN, Farlow MR, Grossberg GT, Graham SM, McDonald S, Gergel I: Memantine treatment in patients with moderate to severe Alzheimer disease already receiving donepezil: a randomized controlled trial. JAMA 2004;291:317-324.

19 McShane R, Areosa Sastre A, Minakaran N: Memantine for dementia. Cochrane Database Syst Rev 2006:CD003154.

20 Gauthier S, Loft H, Cummings J: Improvement in behavioural symptoms in patients with moderate to severe Alzheimer's disease by memantine: a pooled data analysis. Int J Geriatr Psychiatry 2008;23:537-545.

-21 Wilcock GK, Ballard CG, Cooper JA, Loft $\mathrm{H}$ : Memantine for agitation/aggression and psychosis in moderately severe to severe Alzheimer's disease: a pooled analysis of 3 studies. J Clin Psychiatry 2008;69:341-348.

-22 Hope T, Keene J, Fairburn CG, Jacoby R, McShane R: Natural history of behavioural changes and psychiatric symptoms in Alzheimer's disease. A longitudinal study. Br J Psychiatry 1999;174:39-44.

-23 Pitkala KH, Laurila JV, Strandberg TE, Tilvis RS: Behavioral symptoms and the administration of psychotropic drugs to aged patients with dementia in nursing homes and in acute geriatric wards. Int Psychogeriatr 2004; 16:61-74.

-24 Sink KM, Covinsky KE, Newcomer R, Yaffe $\mathrm{K}$ : Ethnic differences in the prevalence and pattern of dementia-related behaviors. J Am Geriatr Soc 2004;52:1277-1283.

25 Mega MS, Cummings JL, Fiorello T, Gornbein J: The spectrum of behavioral changes in Alzheimer's disease. Neurology 1996;46: 130-135.

26 Sink KM, Covinsky KE, Barnes DE, Newcomer RJ, Yaffe K: Caregiver characteristics are associated with neuropsychiatric symptoms of dementia. J Am Geriatr Soc 2006;54: 796-803.

27 Jost BC, Grossberg GT: The evolution of psychiatric symptoms in Alzheimer's disease: a natural history study. J Am Geriatr Soc 1996; 44:1078-1081.

-28 Olin J, Katz IR, Meyers BS, Schneider LS, Lebowitz BD: Provisional diagnostic criteria for depression of Alzheimer disease: rationale and background. Am J Ger Psychiatry 2002:10:129-141.

-29 Aalten P, Verhey FR, Boziki M, Bullock R, Byrne EJ, Camus V, Caputo M, Collins D, De Deyn PP, Elina K, Frisoni G, Girtler N, Holmes C, Hurt C, Marriott A, Mecocci P, Nobili F, Ousset PJ, Reynish E, Salmon E, Tsolaki M, Vellas B, Robert PH: Neuropsychiatric syndromes in dementia. Results from the European Alzheimer Disease Consortium. I. Dement Geriatr Cogn Disord 2007;24:457-463.

-30 Laughren T: A regulatory perspective on psychiatric syndromes in Alzheimer disease. Am J Geriatr Psychiatry 2001;9:340-345.
31 Jeste DV, Meeks TW, Kim DS, Zubenko GS: Research agenda for DSM-V: diagnostic categories and criteria for neuropsychiatric syndromes in dementia. J Geriatr Psychiatry Neurol 2006;19:160-171.

32 Jeste DV, Finkel SI: Psychosis of Alzheimer's disease and related dementias. Diagnostic criteria for a distinct syndrome. Am J Geriatr Psychiatry 2000;8:29-34.

33 Rosenberg PB, Onyike CU, Katz IR, Porsteinsson AP, Mintzer JE, Schneider LS, Rabins PV, Meinert CL, Martin BK, Lyketsos CG: Clinical application of operationalized criteria for 'Depression of Alzheimer's Disease'. Int J Geriatr Psychiatry 2005;20:119127.

34 Mintzer J, Greenspan A, Caers I, Van Hove I, Kushner S, Weiner M, Gharabawi G, Schneider LS: Risperidone in the treatment of psychosis of Alzheimer disease: results from a prospective clinical trial. Am J Geriatr Psychiatry 2006;14:280-291.

35 Aarsland D, Sharp S, Ballard C: Psychiatric and behavioral symptoms in Alzheimer's disease and other dementias: etiology and management. Curr Neurol Neurosci Rep 2005;5:345-354

36 Ballard C, Waite J: The effectiveness of atypical antipsychotics for the treatment of aggression and psychosis in Alzheimer's disease. Cochrane Database Syst Rev 2006: CD003476.

37 Carson S, McDonagh MS, Peterson K: A systematic review of the efficacy and safety of atypical antipsychotics in patients with psychological and behavioral symptoms of dementia. J Am Geriatr Soc 2006;54:354-361.

38 Moretti R, Torre P, Antonello RM, Pizzolato G: Atypical neuroleptics as a treatment of agitation and anxiety in Alzheimer's disease: risks or benefits. Expert Rev Neurother 2006; 6:705-710.

39 Mintzer J, Targum SD: Psychosis in elderly patients: classification and pharmacotherapy. J Geriatr Psychiatry Neurol 2003;16:199206.

40 Liperoti R, Mor V, Lapane KL, Pedone C, Gambassi G, Bernabei R: The use of atypical antipsychotics in nursing homes. J Clin Psychiatry 2003;64:1106-1112.

-41 Rivas-Vazquez RA, Carrazana EJ, Rey GJ, Blais MA, Racher DA: Alzheimer's disease: pharmacological treatment and management. Clin Neuropsychol 2000;14:93-109.

42 Cummings JL, Frank JC, Cherry D, Kohatsu ND, Kemp B, Hewett L, Mittman B: Guidelines for managing Alzheimer's disease. II. Treatment. Am Fam Physician 2002;65: 2525-2534.

43 Rabins PV, Blacker D, Rovner BW, Rummans T, Schneider LS, Tariot PN, Blass DM, McIntyre JS, Charles SC, Anzia DJ, Cook IA Finnerty MT, Johnson BR, Nininger JE, Schneidman B, Summergrad P, Woods SM, Berger J, Cross CD, Brandt HA, Margolis PM, Shemo JP, Blinder BJ, Duncan DL, Barnovitz MA, Carino AJ, Freyberg ZZ, Gray
SH, Tonnu T, Kunkle R, Albert AB, Craig TJ, Regier DA, Fochtmann LJ: American Psychiatric Association practice guideline for the treatment of patients with Alzheimer's disease and other dementias. Second edition. Am J Psychiatry 2007;164:5-56.

44 Gill SS, Bronskill SE, Normand SL, Anderson GM, Sykora K, Lam K, Bell CM, Lee PE, Fischer HD, Herrmann N, Gurwitz JH, Rochon PA: Antipsychotic drug use and mortality in older adults with dementia. Ann Intern Med 2007;146:775-786.

45 Schneeweiss S, Setoguchi S, Brookhart A, Dormuth C, Wang PS: Risk of death associated with the use of conventional versus atypical antipsychotic drugs among elderly patients. CMAJ 2007;176:627-632.

46 Schneider LS, Tariot PN, Dagerman KS, Davis $\mathrm{SM}$, Hsiao JK, Ismail MS, Lebowitz BD, Lyketsos CG, Ryan JM, Stroup TS, Sultzer DL, Weintraub D, Lieberman JA; CATIEAD Study Group: Effectiveness of atypical antipsychotic drugs in patients with Alzheimer's disease. N Engl J Med 2006;355: 1525-1538.

47 FDA Public Health Advisory: Deaths with Antipsychotics in Elderly Patients with Behavioral Disturbances, April 11, 2005; http:// www.fda.gov/Cder/drug/advisory/antipsychotics.htm.

48 Bullock R: Treatment of behavioural and psychiatric symptoms in dementia: implications of recent safety warnings. Curr Med Res Opin 2005;21:1-10.

49 Sink KM, Holden KF, Yaffe K: Pharmacological treatment of neuropsychiatric symptoms of dementia: a review of the evidence. JAMA 2005;293:596-608.

50 Winblad B, Poritis N: Memantine in severe dementia: results of the M-BEST Study (benefit and efficacy in severely demented patients during treatment with memantine). Int J Geriatr Psychiatry 1999;14:135-146.

-51 Altman DG, Schulz KF, Moher D, Egger M, Davidoff F, Elbourne D, Gotzsche PC, Lang T: The revised CONSORT statement for reporting randomized trials: explanation and elaboration. Ann Intern Med 2001;134:663694.

52 Moher D, Schulz KF, Altman DG: The CONSORT statement: revised recommendations for improving the quality of reports of parallel-group randomized trials. Ann Intern Med 2001;134:657-662.

53 van Dyck CH, Tariot PN, Meyers B, Malca Resnick E: A 24-week randomized, controlled trial of memantine in patients with moderate-to-severe Alzheimer disease. Alzheimer Dis Assoc Disord 2007;21:136-143.

54 Cummings JL, Mega M, Gray K, RosenbergThompson S, Carusi DA, Gornbein J: The Neuropsychiatric Inventory: comprehensive assessment of psychopathology in dementia. Neurology 1994;44:2308-2314.

55 Cummings JL: Behavior as an efficacy outcome. Alzheimer Dis Assoc Disord 1997;11 (suppl 4):v-vi. 
56 van der Kam P, Mol F, Wimmers M: Beoordelingsschaal voor oudere patienten (BOP). Deventer, Van Loghum Slaterus, 1971.

57 Gilleard CJ, Pattie AH: The Stockton Geriatric Rating Scale: a shortened version with British normative data. Br J Psychiatry 1977; 131:90-94.

58 Cummings JL, Schneider E, Tariot PN, Graham SM: Behavioral effects of memantine in Alzheimer disease patients receiving donepezil treatment. Neurology 2006;67:5763.

59 Gauthier S, Wirth Y, Möbius HJ: Effects of memantine on behavioural symptoms in Alzheimer's disease patients: an analysis of the Neuropsychiatric Inventory (NPI) data of two randomised, controlled studies. Int J Geriatr Psychiatry 2005;20:459-464.

60 Doody RS, Tariot PN, Pfeiffer E, Olin J, Graham SM: Meta-analysis of 6-month memantine trials in Alzheimer's disease. Alzheimers Dement 2007;3:7-17.

61 Winblad B, Jones RW, Wirth Y, Stöffler A, Möbius HJ: Memantine in moderate to severe Alzheimer's disease: a meta-analysis of randomised clinical trials. Dement Geriatr Cogn Disord 2007;24:20-27.
62 Porsteinsson AP, Grossberg GT, Mintzer J, Olin JT: Memantine treatment in patients with mild to moderate Alzheimer's disease already receiving a cholinesterase inhibitor: a randomized, double-blind, placebo-controlled trial. Curr Alzheimer Res 2008;5:8389.

63 Bakchine S, Loft H: Memantine treatment in patients with mild to moderate Alzheimer's disease: results of a randomised, doubleblind, placebo-controlled 6-month study. J Alzheimers Dis 2008;13:97-107.

64 Peskind ER, Potkin SG, Pomara N, Ott BR, Graham SM, Olin JT, McDonald S; for the Memantine MEM-MD-10 Study Group: Memantine treatment in mild to moderate Alzheimer disease: a 24-week randomized, controlled trial. Am J Geriatr Psychiatry 2006;14:704-715.

65 Cummings J, Olin J: Meta-analysis of neuropsychiatric inventory (NPI) domains in three 6-month trials of memantine in moderate to severe AD. Alzheimers Dement 2006;2:S231.
66 Grossberg GT, Manes F, Allegri R, Gutierrez Robledo LM, Gloger S, Xie L, Jia XD, Perhach JL, Graham SM: A multinational, randomized, double-blind, placebo-controlled, parallel-group trial of memantine extended-release capsule ( $28 \mathrm{mg}$, once daily) in patients with moderate to severe Alzheimer's disease. 11th Int Conf Alzheimer Dis, Chicago, Ill., 2008.

67 Lyketsos CG, Lopez O, Jones B, Fitzpatrick AL, Breitner J, DeKosky S: Prevalence of neuropsychiatric symptoms in dementia and mild cognitive impairment: results from the cardiovascular health study. JAMA 2002; 288:1475-1483.

68 Yaffe K, Fox P, Newcomer R, Sands L, Lindquist K, Dane K, Covinsky KE: Patient and caregiver characteristics and nursing home placement in patients with dementia. JAMA 2002;287:2090-2097.

69 Howard RJ, Juszczak E, Ballard CG, Bentham P, Brown RG, Bullock R, Burns AS, Holmes C, Jacoby R, Johnson T, Knapp M, Lindesay J, O’Brien JT, Wilcock G, Katona C, Jones RW, DeCesare J, Rodger M: Donepezil for the treatment of agitation in Alzheimer's disease. N Engl J Med 2007;357:1382-1392. 